International Journal of Forensic Science \& Pathology (IJFP)

ISSN 2332-287X

\title{
Accidental Smothering during Interrogation: A Case Report
}

Asit Kumar Sikary

Senior Resident, Department of Forensic Medicine \& Toxicology, $2^{\text {nd }}$ Floor, New Forensic Building, All India Institute of Medical Sciences, New Delhi, India.

\begin{abstract}
Accidental smothering is not uncommon and, do occur during detention and interrogation, but not many cases are reported in the literature. Here I am reporting a case of accidental smothering, first from India, where the victim was being interrogated by three accused. When he started shouting for help, they wrapped a brown tape and greenish cloth around the mouth and nose covering both of them. The person initially resisted, but suddenly collapsed and died.
\end{abstract}

Keywords: Interrogation; Adipocere; Artificial Denture; Asphyxia; Excited Delirium.

\section{*Corresponding Author:}

Dr. Asit Kumar Sikary,

Senior Resident, Department of Forensic Medicine \& Toxicology, $2^{\text {nd }}$ Floor, New Forensic Building, All India Institute of Medical Sciences,

New Delhi, India.

Tel: +918130378201

E-mail: bad.snmc@gmail.com

Received: April 10, 2015

Accepted: September 08, 2015

Published: September 10, 2015

Citation: Asit Kumar Sikary (2015) Accidental Smothering During Interrogation: A Case Report. Int J Forensic Sci Pathol. 3(9), 166-168. doi: http://dx.doi.org/10.19070/2332-287X-1500040

Copyright: Asit Kumar Sikary ${ }^{\circ} 2015$. This is an open-access article distributed under the terms of the Creative Commons Attribution License, which permits unrestricted use, distribution and reproduction in any medium, provided the original author and source are credited.

\section{Background}

Smothering is a type of asphyxia caused by obstructing or occluding the external airways i.e. mouth and nose. Death in these cases is either homicidal or suicidal. Accidental is very rare [1]. Accidental suffocation may occur [2] with newborns when the membrane remains around the head after delivery, with infants when they bury their face into the beddings, with drug addicts when they use plastic bags around their head and face during glue-sniffing or when a person falls into some mobile solid which then block the airways [3]. Sometimes, when a gag is placed around the face occluding the mouth and nose, it can cause death by smothering which was only applied to prevent the person from shouting. In these cases, victims are generally elderly and unable to struggle or susceptible to anoxia due to diseases [1].

\section{The Case}

\section{Alleged history}

A 52 year old male was found dead by police personnel in a rented room inside a bed-box in a decomposed condition with a brown tape wrapped around the mouth and nose, and both the ankles tied with the help of pieces of clothes. The body was wrapped in bed-sheets and blanket. The body was brought to the mortuary and preserved in cold storage for two days before postmortem. Meanwhile, police had arrested three accused (husband-wife duo and a friend of them) who gave the details of the incident. According to them, the victim was having illicit relation with the woman. When her husband (one of the accused) came to about the fact, he made his wife to call the person on an instance of having sexual relation with her. When the person reached the specified room, the husband-wife duo, along with one friend tied his both wrists and ankles with pieces of clothes and interrogated him. When he started shouting they put a brown tape and a piece of green cloth around his mouth and nose to silence him. The person first resisted and then suddenly became unconscious after sometimes, and died on the spot. They cut open the tied wrist, wrapped the body in bed-sheets and put the body inside the bedbox in the same room. The body was recovered after 4 days of the incident by the police on instance of room owner when he came across the foul smell of decomposition.

\section{Postmortem Examination}

External Examination: The deceased was wearing a sweatshirt and a pair of pants (Fig 1). Brown adhesive tape with an underlying bluish piece of cloth was found wrapped around the lower part of face covering mouth and nose (Fig 2). Both the ankles were tied with two cloth pieces (Fig 3). All the clothes were soiled with decomposing fluid. Both the tying materials were cut open and preserved. There were no blood stains over the tying material only some staining due to decomposition fluid (Fig 4).

A groove was formed due to the tied material over the face. The mouth was wide open with the tongue being curved forming part of the groove (Fig 5). The upper jaw was having only right $2^{\text {nd }}$ molar teeth. The lower jaw was having a denture which was in place (Fig 6). Both the nostrils obliterated with depressed tip due to the pressure over it. Whitish material was present in the nos- 
trils. No injury was appreciated over the face and neck (Figure 7).

Adipocere had been formed all over the body. No injury was appreciated over the body.

Internal Examination: Due to decomposition changes, no information could be gathered from an internal examination of the organs but the coronaries were patent. No injury was present over the neck structure (Figure 8). Toxicological analysis was negative too.

After complete postmortem examination, cause of death was opined as due to smothering as a result of obstruction to external airways, mouth and nose. No opinion was given on manner of death.

\section{Discussion}

The fact that no injury was present over the face, no blood tinged froth or blood stains were present on the wrapping material (Figure 4) and the artificial denture was in place, is supporting the version of the accused. It shows that they didn't try to smother the person. Keeping all these facts in view, the manner of smothering is supposed to be accidental which is also supported by the preliminary investigation report of the police.

Accidental smothering does occur in forensic settings [3]. A study done by Boghossian E et al [4] on non-chemical suffocation deaths in a 6 year retrospective study, they found that homicidal smothering is not the most common and accidental smothering

Figure 1. Victim with tied mouth-nose and ankles, but the hands are free. Clothes are stained with decomposing fluid.

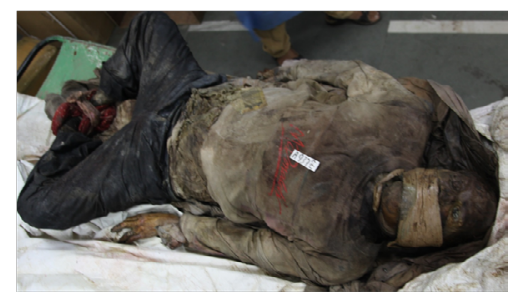

Figure 2. Brown tape covering mouth and nose.

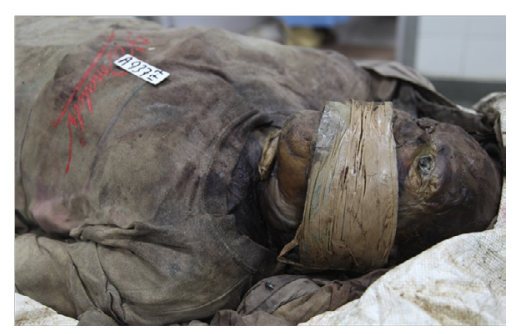

Figure 3. Both the ankles are tied.

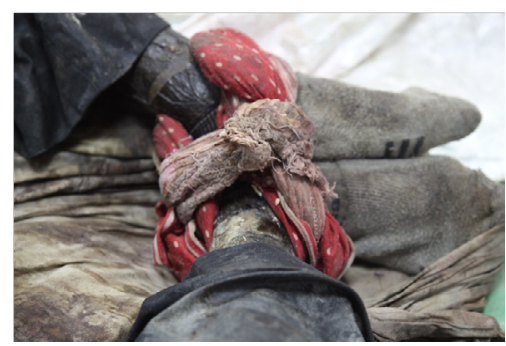

Figure 4. Cloth pieces and brown tape used to obstruct mouth and nose. These are stained with decomposition fluid and nonporous. No blood stain was identified.

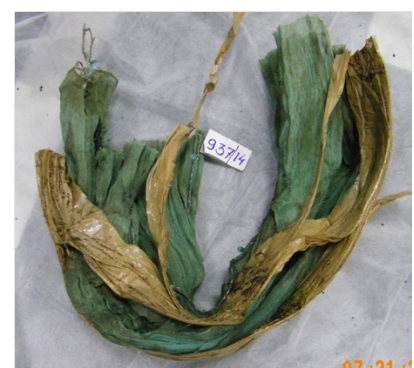


Figure 5. A groove is formed. Mouth wide open and nostrils are obliterated.

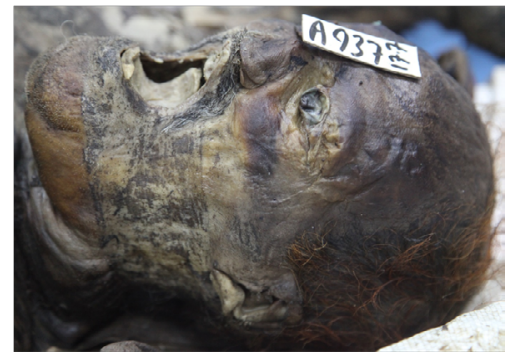

Figure 6. Lower jaw artificial denture is in-situ. No injury to the tongue and lips.

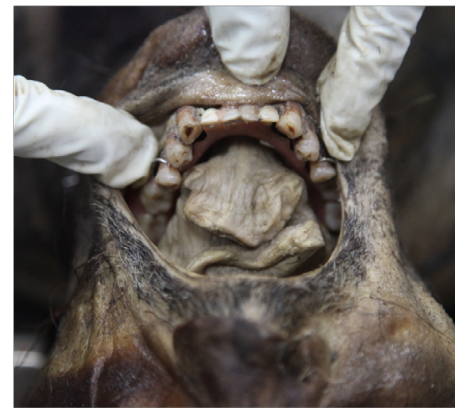

Figure 7. No injury present over the neck.

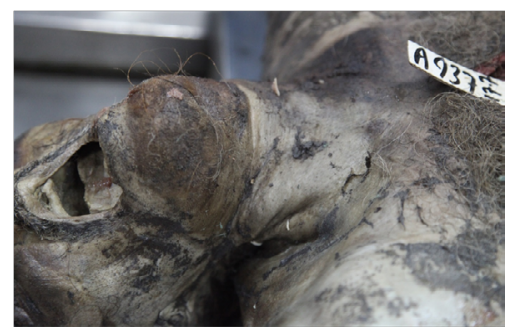

Figure 8. No injury present over the laryngeal structure.

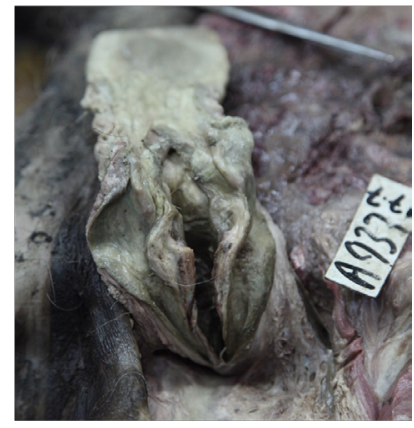

is not unusual.

There are many scenarios where accidental smothering can occur. Suzuki $T$ et al [5] reported a case where a person died while trying to prove his theory on respiration to improve physical exercise. Four pieces of packing tape were found adherent to his mouth and nose.

An unusual case accidental suffocation death was reported by $\mathrm{O}$ Gambhir Singh et al [6] where a person gone to attend the call of nature during the rainy night. The person slipped and stuck his head with some stones. He became unconscious and remained lying there. Due to heavy rain, mud and sand particles started depositing around his mouth and nose, obstructing them. The person found dead in the morning with signs of asphyxia at autopsy.

This case represents accidental smothering during interrogation. Death does occur during interrogation and restrain, especially when a person is in the state of excited delirium condition and put in a position causing positional asphyxia [7]. This same phenomenon may have played a role in the present case too.

\section{References}

[1]. Di Maio VJ, Di Maio DJ (2001) Asphyxia. In: Forensic Pathology. (2nd edtn), CRC Press, London. 230-278.

[2]. Reddy KSN (2012) The Essentials of Forensic Medicine and Toxicology. (31st edtn), K Saguna Devi Publication, Hyderabad. 335-336.

[3]. Saukko P, Knight B (2004) Suffocation and asphyxia. In: Knight's Forensic Pathology. (3rd edtn), Arnold, London. 352-367.

[4]. Boghossian E, Tambuscio S, Sauvageau A (2010) Nonchemical suffocation deaths in forensic setting: a 6-year retrospective study of environmental suffocation, smothering, choking, and traumatic/positional asphyxia. J Forensic Sci 55(3): 646-651.

[5]. Suzuki T, Ikeda N, Harada A, Umetsu K (1992) An unusual case of accidental smothering. Med Sci Law 32(1): 68-70.

[6]. Singh O, Lepcha C, Serma PC (2011) Fatal accidental smothering: A Case Report. J Punjab Acad Forensic Med Toxicol 11(1): 42-43.

[7]. Pollanen MS, Chiasson DA, Cairns JT, Young JG (1998) Unexpected death related to restraint for excited delirium: a retrospective study of deaths in police custody and in the community. Can Med Assoc J 158(12): 1603-1607. 